\title{
Stock Market Volatility and Weak-form Efficiency: Evidence from an Emerging Market
}

\author{
ABID HAMEED and HAMMAD ASHRAF
}

\section{INTRODUCTION}

There exists a vast literature on modeling and estimating aggregate stock market volatility over the past decade [e.g., Choudhry (1996); Mecagni and Sourial (1999) and Kabir, et al. (2000)]. Motivations for undertaking this exercise have been varied. Many value-at-risk models for measuring market risk require the estimation of volatility parameter. Portfolio diversifications and hedging strategies also require information on volatility as a key input. Volatility is defined as tendency of the assets price to fluctuate either up or down. Increased volatility is perceived as indicating a rise in financial risk which can adversely affect investor assets and wealth. It is observed that when stock market exhibit increased volatility there is a tendency on part of the investors to lose confidence in the market and they tend to exit the market. The nexus between volatility and economic fundamentals is still a moot point. Stock prices reflect information and quicker they are in absorbing accurately new information, more efficient is the stock market in allocating resources. The increase in volatility can be attributed to absorption of new information about economic fundamentals or some expectations about them. This kind of volatility is not harmful as there is no social cost associated with it. But if increased volatility is not explained by the level indicated by the fundamental economic factors, there is a tendency that stocks will be mispriced and this will lead to misallocation of resources [Karmaka (2006)].

Efficient markets hypothesis (EMH) asserts that in an efficient market price fully reflect available information. This implies that investor can expect to earn merely riskadjusted return from an investment as prices move instantaneously and randomly to any new information. Efficiency is defined at three different levels, according to the level of information reflected in the prices. Three levels of EMH are expressed as follows: weakform, semi-strong and strong form. Weak-form version of EMH asserts that prices of financial assets reflect all information contained in the past prices. Semi-strong version postulates that prices reflect all the publicly available information. Lastly, strong-form posits that prices of financial assets reflect, in addition to information on past prices and publicly available information, inside information [Fama $(1970,1991)]$.

Abid Hameed <abid.hameed@sbp.org.pk> is Economist at State Bank of Pakistan, Karachi, and Hammad Ashraf <hmd777@ @otmail.com> is Assistant Professor at Bahria University, Islamabad.

Authors' Note: The authors would like to state that the views expressed in this paper are those of the authors and do not necessarily represent those of the organisations where they work. 
Why do we care if stock market is efficient or not? Stock market acts as an intermediary and channels funds from savers to firms who utilise it to carry out projects. Efficient markets are a necessary prerequisite if it is desired that funds should be allocated to the highest-valued projects. This is possible only if stock prices are efficiently priced i.e. reflect the fundamental value of future discounted cash flows. Also, to the extent that capital markets are efficient, it is easier for the firm to raise capital as the market performs the price discovery process i.e. it determines the price at which market players are willing to exchange claims on firm's future cash flows. Furthermore, if the general perception prevailing in the market is that prices accurately reflect information, participations cost will be low and stock market will successfully perform its function of channeling resources to productive projects. From a policy perspective evidence of capital market efficiency spells out a limited role of the government in the capital markets. Pakistan's equity market being an emerging market, it seems appropriate to test for weak-form efficiency.

Chakraborty (2006) investigates the weak-form efficiency of the Pakistani stock market using daily closing prices from January 1st 1996 to 31st December 2000. Employing variance ratio and serial correlation tests, random walk hypothesis is rejected.

Husain and Uppal (1999) examine stock market volatility in Pakistan using daily stock prices on 36 companies, 8 sector indices and a market index using ARCH and GARCH models from January 1, 1989 to December 30, 1993. Their result point out that GARCH $(1,1)$ is the appropriate representation of conditional variance. They also find evidence of persistence in variance in returns. Furthermore, there results show that persistence in volatility tends to decline significantly after liberalisation of the capital markets.

In Pakistan there is a general perception that high volatility observed in the stock market is due to insider trading by collusive brokers. A recent study by Khawja and Mian (2005) has empirically established that stock prices in Pakistan are manipulated by colluding stock brokers. To the extent that manipulation increases volatility it will increase the participation cost of the investors. This will discourage outside investors to participate in the market. They point out that such costs are one of the factors, which can help solve the puzzle of financial underdevelopment. They further identify direct costs to comprise of large transfer of wealth from outsiders to inside manipulators, which is likely to influence the depth of the market and adversely affect its intermediary role. To the extent that insider trading affects stock market, it does not bode well for the viability of EMH in context of Pakistani stock market.

In light of the above, it is important to empirically identify the volatility pattern of stock returns in Pakistan. More specifically, the objectives of the present study are as follows: (1) to test if volatility of returns is time varying; (2) to test for the existence of a viable risk-reward relationship exists i.e. an investor is rewarded for taking additional risk; and (3) to measure the impact of Securities and Exchange Commission (SECP) reforms and 9/11 incident on the volatility of returns.

This paper is divided into six sections. Section II provides a brief overview of Pakistani stock market. Section III discusses methodology and delineates the different approaches to modeling volatility. Section IV describes the data. Section V discusses estimation and results. Finally, Section VI sums up the conclusion. 


\section{BACKGROUND ON STOCK MARKET}

The Pakistani stock market comprises of three exchanges, namely Karachi stock exchange, Lahore stock exchange and Islamabad stock exchange. For the purpose of this study we will focus exclusively on Karachi stock exchange (KSE), which is the main exchange of the country.

KSE has come a long way. It was established on 18th September, 1947. The development of KSE over the years can be gauged by looking at the trend in trading statistics listed in Table 1. Most of the indicators such as market capitalisation, total turnover and average daily turnover show a rising trend.

Table 1

Selected Indictors for Karachi Stock Exchange

\begin{tabular}{lccccc}
\hline Indicators & 2001 & 2002 & 2003 & 2005 & 2006 (March) \\
\hline Listed Companies & 747 & 711 & 701 & 661 & 663 \\
Market Cap. & $296,143.7$ & $595,205.63$ & $951,446.5$ & $274,6558.97$ & $3257,061.81$ \\
Daily Turnover & 96.91 & 167.10 & 308.81 & 338.54 & 594.63 \\
Total Turnover & $23,069.71$ & $14,627.20$ & $76,380.08$ & $91,447.76$ & 26893.56 \\
Volume & & & & & \\
KSE-100 Index (31st Dec.) & 1273.07 & 2701.42 & 4472 & 9556.61 & 11485.90 \\
\hline
\end{tabular}

Source: Karachi Stock Exchange.

The revitalisation of KSE took place in early 2000 within a process of deregulation and privatisation. Capital market reforms carried out in late $90 \mathrm{~s}$, revitalised the stock exchanges. More specifically, significant reforms were introduced in the area of risk management, governance, transparency, and investor protection. These reforms have been somewhat successful as is evidenced by the relative reduction in volatility vis-à-vis the prereform era. Government's privatisation strategy which entailed selling off shares of state controlled enterprises by listing them on the stock exchange has broadened and deepened the capital market. This was witnessed by the accelerated rise in the KSE-100 index rising by 65 percent to a record level of 10,303 on March 15th, 2005. Unfortunately, some of these gains have been lost, by exit of the small investor, due to bearish stance of the market when it dropped to a low level of 6939 on April 12th, which amounted to a decline of 32.7 percent. Furthermore, the protracted uncertainty regarding the badla financing and switch over to some viable form of margin financing has contributed to volatility in the market. Notwithstanding the above developments, KSE has risen to become one of the best performing market among the class of emerging stock markets.

To protect investor's interest from excessive volatility in prices, SECP as a part of its capital market reforms introduced circuit breakers in December 2001, hereafter referred to as regime 2. They were structured in a manner that for downward circuit breaker a price of scrip could not fall below 5 percent or Rs 1 whichever is higher, from the closing price of the previous day. Similarly, for upward circuit breaker a price of scrip could not rise more than 7.5 percent or Rs 1.5 whichever is higher, from the closing price of the previous day. Prior to December 2001, referred to as regime 1, a scrip was declared spot if price moved by 25 percent or Rs 5, whichever is higher. After March 2005, referred to as regime 3 , a new system was devised where a scrip's price was allowed to drop by 5 percent on the first day, 10 percent the second day and by 20 percent on the 
third day. In this paper we focus our analysis only on regime 2 as regime 1 and 3 were never binding in the sample period under consideration.

Introduction of circuit breakers and their usefulness is moot point. Price limits may provide a cooling off period preventing investors from panicking and leading to reduction in volatility especially in uncertain environments when there is tendency to overreact to news. On the other hand, price limits may truncate the distribution of price changes for individual stock and produce irregularly observed or missing data as equilibrium price is no longer available when price limit becomes binding. Also, price limits may hamper the price discovery process by acting as a barrier to market clearing mechanism. Furthermore, liquidity problems may also arise when buyers and seller are unwilling to enter the market in anticipation of further price decreases or price increases.

\section{METHODOLOGY}

In this paper a generalised $\operatorname{GARCH}(p, q)$ model is utilised to model volatility and test for weak-form efficiency of the stock returns. In this section we outline the recent developments in modeling the conditional volatility of stock returns.

Modeling of volatility has come a long way. A crude measure of volatility, standard deviation, is the standard tool applied in the financial markets. This measure estimates the sample standard deviation of the returns over a sample period. The problem with this approach lies with the choice of sample period. If the sample period is too long it may not be relevant for today and if it too short, it will tend to be too noisy. Furthermore, an asset holder is concerned with the forecast of the rate of return and its variance over the holding period, the so-called conditional variance. He is least concerned with the long-run forecast of the variance, the so-called unconditional variance. One way to resolve the above problem is to resort to estimating rolling standard deviation. While this approach provides forecast of the conditional variance, its drawback is that it equally weighs average of the squared residuals over the pre-defined rolling window. Moreover, this approach is criticised on the grounds that it attaches a weight of zero to observations that fall before the pre-defined rolling window. Engle (1982) proposed an autoregressive conditionally heteroscedastic (ARCH) model for specifying conditional volatility that incorporates the common sense logic that observations belonging to the recent past should get higher weights than those belonging to the distant past i.e. the model adopts an unequal weighting structure that evolves according to an autoregressive scheme. The weights are estimated using the sample data. Bollerslev (1986) proposed a generalised ARCH model (GARCH) model which essentially generalises the ARCH model by modeling the conditional covariance as an ARMA process. This $\operatorname{GARCH}(p, q)$ can be represented for stock returns $\left(y_{t}\right)$ and stock return volatility $\left(\sigma_{t}^{2}\right)$ as follows:

$$
\begin{aligned}
& y_{t}=\mu+\sum_{j \in J} \rho_{j} y_{t-j}+\varepsilon_{t} \\
& \varepsilon_{t} \sim N\left(0, \sigma_{t}^{2}\right) \\
& \sigma_{t}^{2}=\beta_{0}+\sum_{i=1}^{i=q} \gamma_{i} \varepsilon_{t-i}^{2}+\sum_{i=1}^{i=p} \beta_{i} \sigma_{t-i}^{2} \ldots \quad \ldots \quad \ldots \quad \ldots \quad \ldots \quad \ldots \quad \ldots
\end{aligned}
$$


In the above setup, $\left(y_{t}\right)$ is referred to as the mean equation and the $\left(\sigma_{t}^{2}\right)$ represents the variance equation. The mean equation is specified as an autoregressive moving average process, ARMA $(p, q)$, which assumes that a time series is a linear combination of its past values and as well as current and past values of random errors. In this framework weakform efficiency is established if the coefficients on the ARMA terms are statistically insignificant. The choice of $p, q$ and $J$ are identified using standard time series techniques.

Engle, Lilien and Robins (1987) suggested an ARCH-M specification where the conditional variance of assets returns enters into conditional mean equation. The basic insight is that an investor should be rewarded for taking additional risk by obtaining a higher return. To the extent, that an asset's riskiness can be measured by its variance, the risk premium will be an increasing function of the conditional variance of the returns. An extension of ARCH-M model specifies conditional variance as a GARCH process and then adds the conditional variance to the mean equation. The resulting specification called GARCH-M is given as follows:

$$
\begin{aligned}
& y_{t}=\mu+\sum_{j \in J} \rho_{j} y_{t-j}+\sum_{k \in K} \varphi_{k} \sigma_{t-k}+\varepsilon_{t} \\
& \varepsilon_{t} \sim N\left(0, \sigma_{t}^{2}\right) \\
& \begin{array}{lllllll}
\sigma_{t}^{2}=\beta_{0}+\sum_{i=1}^{i=q} \gamma_{i} \varepsilon_{t-i}^{2}+\sum_{i=1}^{p} \beta_{i} \sigma_{t-i}^{2} & \ldots & \ldots & \ldots & \ldots & \ldots
\end{array}
\end{aligned}
$$

In the above formulation, a positive and significant risk coefficient $(\varphi)$ will imply that market rewards investors for taking additional risk by reaping a higher return.

To summarise, the above models are consistent with the following common stylised effects observed in the financial data: (1) Leptokurosis- financial returns tend to have distributions that have fat tails and exhibit excess peakedness at the mean; (2) Volatility clustering- tendency for volatility to exhibit clustering. Large returns, positive or negative are expected to follow large returns and smaller returns, positive or negative, are expected to follow smaller returns; and (3) Leverage effects-tendency for returns to exhibit asymmetry i.e. volatility rises more following a large price fall than following a price rise of the same magnitude.

\section{DATA}

For the purposes of testing weak-form efficiency and modeling of conditional volatility of stock returns, daily closing values of the KSE-100 are examined over the period December 1998 to March 2006. The daily return series comprise of 1764 observation. The daily returns are computed as the logarithm of ratio of the price today to price yesterday. Table 2 summarises the descriptive statistics of the return series. From Table 2 it is seen that KSE-100 series has high mean value of .12 per cent per trading day. The standard deviation is 6.12 per cent per trading day, reflecting a high risk market. The value of kurtosis, which is a measure of whether data are peaked or flat relative to normal distribution, is 5.59 which indicates that data is leptokurtic i.e. it is characterised 
Table 2

Descriptive Statistics: Returns

\begin{tabular}{lc}
\hline Sample & December $1998-$ March 2006 \\
\hline Mean & 0.0012 \\
Median & 0.0019 \\
Maximum & 0.0850 \\
Minimum & -0.0774 \\
Std. Dev. & 0.0162 \\
Skewness & -0.2254 \\
Kurtosis & 5.7940 \\
Jarque-Bera & 588.20 \\
Probability & 0.0000 \\
\hline
\end{tabular}

by simultaneous occurrence of distinct peak near the mean and exhibition of fat tails. The value of skewness, which measures the asymmetry in the distribution is -.22 which indicates that returns are negatively skewed. The above statistics imply that returns are not normally distributed. This conclusion is further validated by the significant JarqueBera test for normality.

To examine the persistence in volatility we examine the squared returns. The autocorrelations coefficients of squared returns are presented in Table 3. The significant autocorrelation coefficients reflect the presence of volatility clustering in the returns.

Table 3

Autocorrelations: Squared Returns

\begin{tabular}{ccccc}
\hline Lags & ACF & PAC & Q-Statistic & Probability \\
\hline 1 & 0.275 & 0.275 & 133.76 & 0.0000 \\
2 & 0.262 & 0.202 & 255.50 & 0.0000 \\
3 & 0.244 & 0.147 & 360.71 & 0.0000 \\
4 & 0.173 & 0.048 & 413.73 & 0.0000 \\
5 & 0.140 & 0.022 & 448.34 & 0.0000 \\
6 & 0.093 & -0.012 & 463.69 & 0.0000 \\
7 & 0.094 & 0.019 & 479.25 & 0.0000 \\
8 & 0.099 & 0.039 & 496.25 & 0.0000 \\
9 & 0.097 & 0.039 & 513.06 & 0.0000 \\
10 & 0.089 & 0.035 & 527.04 & 0.0000 \\
\hline
\end{tabular}

The above findings are in consort with stylised facts observed in the financial time series, as outlined earlier.

In Figure 1 below we present graph for the KSE-100 return series. Eyeballing the graph one can readily observe that volatility after May 2002 seems to have declined. This could be due to numerous initiatives taken by the SECP under its 'Capital Market Reforms'. Some of the initiatives undertaken are as follows: implementation of $\mathrm{T}+3$ system, rationalisation of risk management measures and imposition of circuit breakers. 
Fig. 1. Returns from December 1998 to March 2006

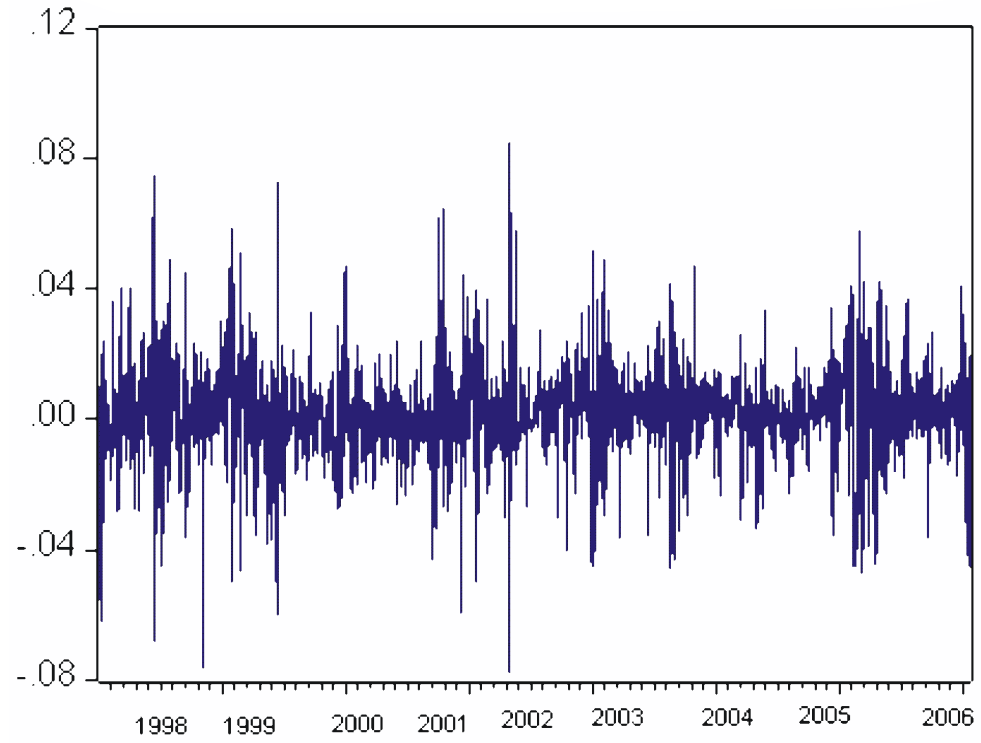

\section{ESTIMATION AND RESULTS}

The first step in modeling the GARCH process involves specifying a model for the return series. An $\operatorname{ARMA}(1,1)$ model is identified for the return series based on Box and Jenkins methodology. An ARCH- LM test is carried out to ensure that the underlying process is in consort with the postulated GARCH process. Testing for ARCH error involves two steps. In the first step returns are estimated as an $\operatorname{ARMA}(1,1)$ process. In the second step, squared residuals from the above regression are regressed on a constant and 4 lags. Under the null of no ARCH errors the test statistic is distributed a $\chi^{2}$. Both the Ftest and LM statistic are very significant, indicating the presence of ARCH errors in the KSE-100 returns. As the ARCH test indicates the presence of non-linearity, we proceed to model the return series as a GARCH process. An ARMA(1,1)-GARCH(1,1)-M model is specified to characterise the volatility and to test for the weak-efficiency of the KSE100 returns. The estimated model is given as follows:

$$
\begin{aligned}
& y_{t}=\mu+\rho y_{t-1}+\varphi \sigma_{t-1}+\tau \varepsilon_{t-1}+\lambda D_{t}+\varepsilon_{t} \\
& \varepsilon_{t} \sim N\left(0, \sigma_{t}^{2}\right) \\
& \sigma_{t}^{2}=\beta_{0}+\gamma \varepsilon_{t-1}^{2}+\beta_{1} \sigma_{t-1}^{2}+\beta_{2} D_{t} \quad . .
\end{aligned}
$$

The above formulation is similar to the general form presented in Equation (2) with the exception that the volatility equation includes a dummy variable. We estimate two models which are similar in all respects but in the choice of the dummy variable. In the first model (Model 1) we include a dummy $\left(D_{1}\right)$ to capture the effect of introduction of circuit breakers (regime 2) on the volatility of the returns. $D_{1}$ takes the value of 1 from December 2001 to March 2005 and 0 otherwise. In the second model (Model 2) the dummy $\left(D_{2}\right)$ tries to capture the impact of $9 / 11$ on the volatility of the stock returns. $D_{2}$ takes a value of one for 9th September 2001 and 0 otherwise. 
The models are estimated using maximum likelihood method under the assumption that errors are conditionally $t$-distributed. The choice of $t$-distribution is necessitated due to the presence of excess kurtosis in the return series. The log likelihood function is maximised using Marquardt iterative algorithm to search for optimal parameters. The results tabulated in Table 4 show that the risk coefficient $\varphi$ is of almost similar magnitude, insignificant, and has the wrong sign in both models. This implies that risk-return relationship as postulated by the portfolio theory does not exist for Pakistani stock market.

This is a common finding observed in the literature for studies that employ GARCH models. Fraser and Power (1997) fails to establish this relationship for a sample of nine emerging economies. Omet et al. (2002) were partially able to find evidence of risk-return relationship for Jordon using a sample of five indexes.

Table 4 also reports the AR(1) and MA(1) coefficients, which are found to be individually and jointly significant, and have similar magnitudes for both the models. This result indicates that returns series exhibits departure from weak-form efficiency, as past information can be used to predict future prices.

The significance of $\gamma$ and $\beta_{1}$, in both models, support the hypothesis that conditional volatility changes over times due to volatility clustering, as implied by a significant $\gamma$, and due to temporal dependence, as reflected by the significant $\beta_{1}$. Furthermore, the sum of $\gamma+\beta_{1}$ a measure of volatility persistence is very high which implies that effects of shocks tend to last for long periods before they die out. At the same time the sum is less than unity, which points to the stability of the model.

Table 4

ARMA(1,1)-GARCH(1,1)-M Estimates of Returns

\begin{tabular}{lcc}
\hline Variables & Model 1 & Model 2 \\
\hline$\mu$ & -0.0004 & -0.0004 \\
& $(0.33)$ & $(-0.36)$ \\
$\rho$ & $0.9393^{* * *}$ & $0.9082^{* * *}$ \\
& $(29.34)$ & $(17.46)$ \\
& 0.0323 & 0.0346 \\
$\tau$ & $(0.42)$ & $(0.483)$ \\
& $-0.8999^{* * *}$ & $-0.8701^{* * *}$ \\
$\lambda(\mathrm{D} 1)$ & $(-22.44)$ & $(-14.10)$ \\
& $0.00268^{* * *}$ & \\
$\lambda(\mathrm{D} 2)$ & $(2.77)$ & $0.00315^{* *}$ \\
& & $(3.54)$ \\
$\beta_{0}$ & $1.98 \mathrm{e}-05^{* * *}$ & $2.07 \mathrm{e}-05^{* * *}$ \\
& $(3.88)$ & $(3.75)$ \\
$\gamma$ & $0.2427^{* * *}$ & $0.2431^{* * *}$ \\
$\beta_{1}$ & $(6.24)$ & $(6.28)$ \\
$\beta_{2}\left(\mathrm{D}_{1}\right)$ & $0.7263^{* * * *}$ & $0.7294 * * *$ \\
$\beta_{2}\left(\mathrm{D}_{2}\right)$ & $(20.63)$ & $(21.31)$ \\
& $-8.36 \mathrm{e}-06^{* * *}$ & \\
\hline
\end{tabular}

Numbers in parenthesis are $z$-values. $*, * *, * * *$ represent significance at 10,5 and 1 percent, respectively. 
We find that in Model 1 the coefficient $\beta_{2}$ (D1) capturing the impact of circuit breaker regime on return volatility is significant with the expected sign but has a very small magnitude. The coefficient on $\lambda$ (D1) which measures the impact of circuit breaker on returns is significant with a positive sign indicating that imposition of circuit breaker regime has slightly improved the returns. This implies that the data does not support the assertion that circuit breakers hamper the price discovery process.

The above results imply that SECP's introduction of circuit breakers has had a partial success: reduction in volatility albeit of a very small magnitude and a positive impact on return. Given that impact on volatility is of very small magnitude, it seems that overall impact of circuit breaker can be termed as neutral.

In Model 2 the coefficient $\beta_{2}$ (D2) meant to capture the impact of 9/11 on volatility turns out to be significant albeit with a negative sign. The model predicts that volatility has decreased, although by a very small amount. This finding is contrary to the widely held conjecture that $9 / 11$ incident has led to increase in volatility. It is held that $9 / 11$ incident led to massive inflows of capital, which were invested in the stock market, thereby influencing its volatility. Furthermore, the coefficient on $\lambda$ (D2) measuring the impact of $9 / 11$ on returns shows a significant albeit a very small positive impact. This implies that $9 / 11$ incident led to a very small increase in returns.

Finally, both models provide a good fit as is evidenced by absence of serial correlation in standardised squares residuals.

\section{CONCLUSION}

There exists a vast literature on modeling and estimating aggregate stock market volatility over the past decade. Motivations for undertaking this exercise have been varied. Many value-at-risk models for measuring market risk require the estimation of volatility parameter. Portfolio diversifications and hedging strategies also require information on volatility as a key input. Furthermore, efficient markets are a necessary prerequisite if it is desired that funds should be allocated to the highest-valued projects. This is possible only if stock prices are efficiently priced i.e. reflect the fundamental value of future discounted cash flows. Also, to the extent that capital markets are efficient, it is easier for the firms to raise capital as the market performs the price discovery process i.e. it determines the price at which market players are willing to exchange claims on firm's future cash flows.

In this paper an attempt has been made to model the volatility of stock returns for the Pakistani stock market and to test for weak-form efficiency. Results point out that returns exhibit persistence and volatility clustering. Weak-form efficiency hypothesis is rejected as it is found that past information helps in predicting future prices. Mean variance hypothesis does not hold for Pakistani stock market as no evidence is found that investors are rewarded for taking increased risk.

The impact of SECP reforms efforts, as captured by introduction of circuit breakers, on returns and returns volatility is found to have a small positive and dampening effect, respectively. Given the very small decline in volatility and a small positive impact on returns, it seems that the overall policy impact can be characterised as neutral. Lastly, it is found that our estimates lead us to believe that 9/11 incident has led to increase in returns and a decrease in volatility which is in contrast to the widely held 
conjecture that $9 / 11$ incident led to massive inflows of capital which were invested in the stock market thereby influencing its volatility in a positive manner.

\section{REFERENCES}

Bollerslev, T. (1986) Generalised Autoregressive Conditional Heteroskedasticity. Journal of Econometrics 31, 307-322.

Chakraborty, M. (2006) Market Efficiency for Pakistan Stock Market: Evidence from Karachi Stock Exchange. South Asia Economic Journal 7:1, 67-81.

Choudhry, T. (1996) Stock Market Volatility and Crash of 1987: Evidence from Six Emerging Countries. Journal of International Money and Finance 15:6, 969-981.

Engle, R. (1982) Autoregressive Conditional Heteroskedasticity with Estimates of the Variance of UK Inflation. Econometrica 50, 987-1008.

Engle, Lilien, and Robins (1987) Estimating Time-Varying Risk Premia in the Term Structure: The ARCH-M Model. Econometrica 55, 391-407.

Fama, E. (1970) Efficient Capital Markets: A Review of Theory and Empirical Work. The Journal of Finance 25:2, 387-417.

Fama, E. (1991) Efficient Capital Markets: II. The Journal of Finance 46:5, 1575-1617.

Fraser, P. and D. Power (1997) Stock Return Volatility and Information: An Empirical Analysis of Pacific Rim, USA and UK Equity Markets. Applied Financial Economics 7, 241-53.

Husain, F. and J. Uppal (1999) Stock Returns Volatility in an Emerging Market: The Pakistani Experience. Pakistan Journal of Applied Economics 15:1\&2, 19-40.

Kabir, H., A. M. Islam, and S. A. Basher (2000) Market Efficiency, Time-Varying Volatility, and Equity Returns in Bangladesh Stock Market. University of New Orleans, Louisiana. (Working Paper 13-00.)

Karmaka, M. (2006) Stock Market Volatility in the Long Run, 1961-2005. Economic and Political Weekly, 1796-1802.

Khawja, A. I. and A. Mian (2005) Unchecked intermediaries: Price Manipulation in an Emerging Stock Market. Journal of Financial Economics 78:1, 203-241.

Mecagni, M. and M. S. Sourial (1999) The Egyptian Stock Market: Efficiency Tests and Volatility Effects. Washington, DC. (IMF Working Paper No. WP/99/48.)

Omet, G., M. Khasawneh, and J. Khasawneh (2002) Efficiency Tests and Volatility Effects: Evidence from the Jordanian Stock Market. Applied Economic Letters 9, 817-821. 


\section{Comments}

The authors have chosen a very important topic for empirical investigation. They investigate the issue of 'the stock market volatility and week form efficiency' in a rigorous manner. The study has multiple objectives. (1) Test that volatility pattern is time varying, (2) Test for risk reward, (3) Measure the impact of 9/11 event and securities and exchange commission (SECP) reforms. I would like to congratulate them for a very competent and dexterous work. They clearly define all variables and use well defined methodology. A large number of tests as well as graphical method have been used to analyse characteristics of data on returns such as mean, median, standard deviation, Skewness, Kurtosis, Jarque Bera test before estimation etc., which is ignored by many researchers.

However, I have some minor comments on the paper.

- The study reports that in late 1990s, reforms are introduced in the area of risk management, governance, transparency, and investor protection. It would be very useful if authors give a brief description of the reforms. They may add as a footnote.

- Auto regressive moving average (ARMA) model assume that time series is a linear combination its current and past value of random error. They may face auto correlation problem? Did they check for that?

- On page 8 they wrote that they have used 'standard time series technique', which is not enough. The authors should explain the method used in the studies.

- Why they have used dummy for regime I only to test impact of circuit breaker. While paper mentioned there are three regimes, (1) December 2001 to March 2005 is defined as regime I, (2) Prior to 2001 is regime II, (3) Post 2005 period is regime III. Therefore, two dummies can be introduced to differentiate the impact over different regimes. Similarly, dummy for $9 / 11$ event can be introduced in the same regression why they have estimated separate regression. Regime II also captures the impact of 9/11 as both occurred in overlapping period.

- The results show that risk-return relationship does not exist, but did not explain why? The reason may be the lack of competitiveness or some other?

- Last the results show that 9/11 event has led to decrease in volatility. From this what we conclude? This kind of events should happen? The authors also indicate that the finding is contradictory to the general view of increase volatility due to September 11 event. Then authors indicate that this decline is due to large inflow of foreign capital from Pakistani national residing outside Pakistan. This indicates actually it is inflow of capital which reduced volatility. I think the relation should be discussed with reference to capital inflow. 
- The efficient market hypothesis suggests that stock markets are 'inforamtion efficient'. That is any new information relevant to the markets is spontaneously reflected in the stock prices. This may be due to the collusion behaviour of the brokers. A consequence of this is that past prices cannot have any predictive power for future prices once the current prices have been used as explanatory variables. Or we can say that future prices depends only on arrival of new information that was unpredictable today hence it is based on surprise information. But I still doubt if prices incorporate correct information if they are result of collusion behaviour of the brokers.

- If the prices reflect the correct information then an important policy come from this research is that promotion of research and development in brokerage firms, which can help to reduce the sharp fluctuations.

- The study can be extended to test the hypothesis of semi-strong efficiency of stock market by directly incorporating the information publicly available-published in daily Business Recorder.

I found a very good paper [Ali and Mustafa (2001)] on the same issue. Hameed and Ashraf may get some help from that paper to extend the present research.

Pakistan Institute of Development Economics,

Rizwana Siddiqui Islamabad.

\section{REFERENCE}

Ali, Salman S. and K. Mustafa (2001) Testing Semi-strong form Efficiency of Stock Market. The Pakistan Development Review 40:4, 651-674. 